\title{
Incidencia de la legislación laboral en las condiciones del empleo juvenil
}

\author{
Raúl GonZÁlez y Marielos GarCía \\ Universidad Centroamericana "José Simeón Cañas"
}

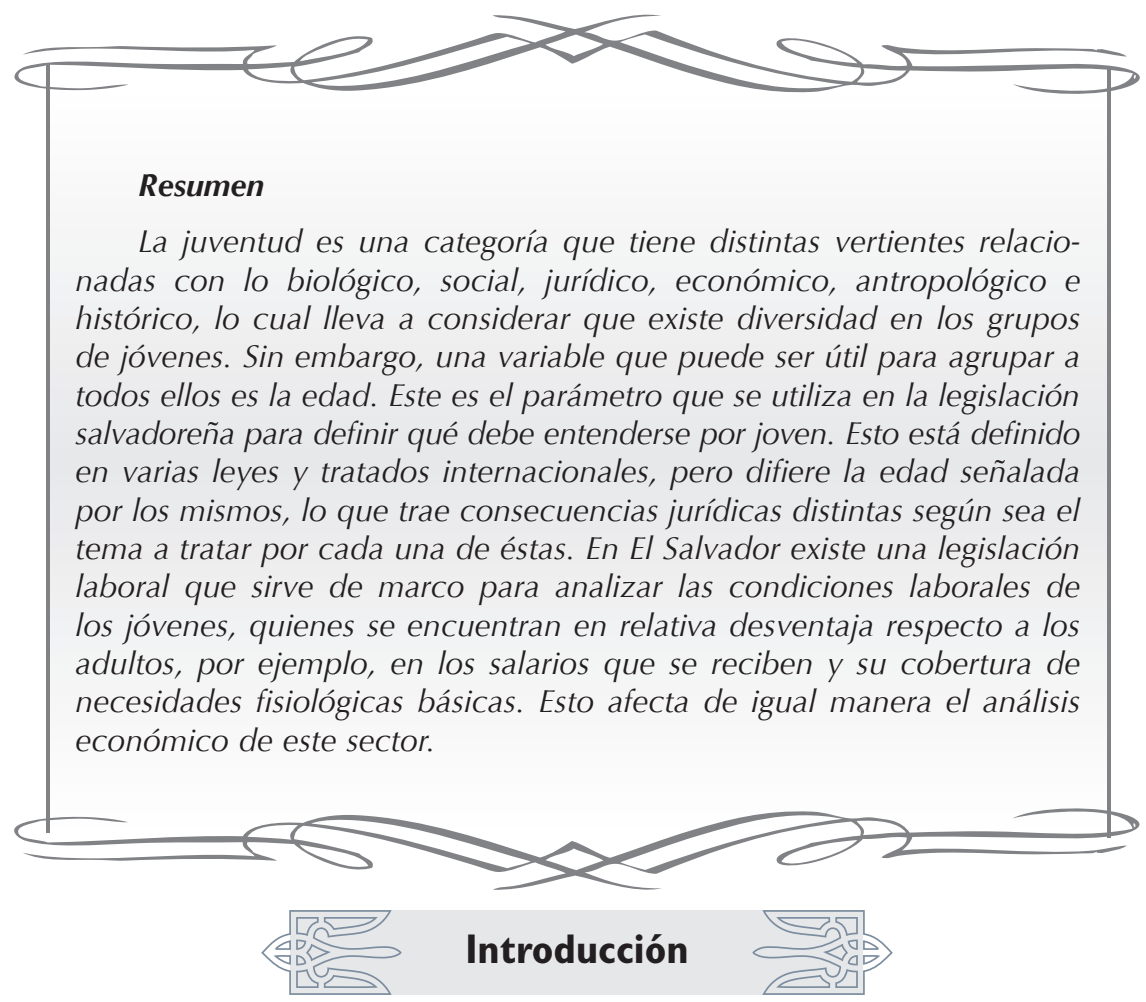

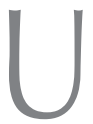
n grupo etario importante dentro del mercado laboral salvadoreño son los jóvenes, puesto que conforman un porcentaje considerable dentro de la población económicamente activa. En este sentido, es necesario evaluar el panorama actual desde la perspectiva jurídica y económica para com- prender cómo afectan estos factores sus condiciones laborales.

Este artículo se divide en cuatro partes. La primera aborda la definición de juventud desde diversas perspectivas; en la segunda, se analiza la legislación laboral que incide en las condiciones laborales 
de los jóvenes; en la tercera, se presenta un panorama general de los jóvenes en el mercado de trabajo; por último, se plantean casos de estudio de los call centers desde una perspectiva jurídica con el objetivo de contrastar lo que expresa la ley y si en estos casos se respeta.

En El Salvador, el mercado de trabajo presenta una heterogeneidad entre las condiciones de los distintos grupos etarios; así se puede visualizar que uno de los grupos que enfrenta mayores dificultades son los jóvenes, por ejemplo, para ubicarse en un empleo decente. Antes de presentar la situación de los jóvenes en el mercado de trabajo, desde una perspectiva jurídica y económica, es importante plantear algunas ideas relacionadas con quiénes son incluidos en esta categoría, que es compleja por los distintos elementos que abarca.

\section{Concepto de juventud}

La definición de la juventud es compleja porque incorpora distintos elementos biológicos, culturales, históricos, sociales, económicos, psicológicos y antropológicos, que desde la perspectiva de diversos autores no es posible dejar de lado para delimitar más acertadamente qué significa ser joven. Tal como plantea Urcola (2003: 41), "si bien podemos afirmar que la juventud corresponde a una etapa biopsicológica del ciclo vital, también es cierto que se constituye como una posición socialmente construida y económicamente condicionada".

Desde una perspectiva social e histórica, lo que se considera juventud es una categoría social que está determinada por la sociedad. Asimismo, ésta depende del poder que tienen los adultos (relaciones de poder), quienes establecen la cultura dominante. En este sentido, Iciar (2003: 11) plantea que:

Algunos han definido a los jóvenes como aquellos que ya no pueden seguir siendo considerados niños, pero que todavía no son adultos. Otros, como Bourdieu, remiten la juventud a las relaciones de poder entre las generaciones, es decir, los jóvenes son los que luchan por el poder frente a los viejos. Los teóricos del desarrollo humano coinciden en que la juventud es el período de la vida que con mayor intensidad evidencia el desfase entre las dimensiones biológicas, psicológicas y socioculturales.

Según Iciar (2003: 13), se han dado cuatro tendencias que han marcado la concepción de la juventud: 
- Juventud como etapa sin valor real por ser transitoria. La juventud es transitoria y su sentido está en el futuro, al llegar a la adultez.

- La juventud como consumidora de recursos, pero no aportadora al desarrollo de la sociedad. Se ve a los jóvenes como una carga, y no como sujetos que pueden aportar cultural y socialmente a los procesos de desarrollo de la sociedad.

- Concepción idealizada sobre la juventud. Se idealiza a los jóvenes ya sea, considerándolos peligrosos o colocándolos en el plano de lo puro y frágil.

- La juventud como grupo homogéneo. Se homogeniza a la juventud, sin tomar en cuenta que las personas de un mismo grupo etario son distintas, así como sus necesidades, cultura, religión, etc.

A partir de esto, es importante definir cuáles son los límites de la juventud y delimitar los elementos como formas y categorías que permitan ordenar la heterogeneidad que se encuentra en esta etapa.

\subsection{Perspectiva biopsicosocial}

Existen distintas variables que "marcan y separan profundamente la realidad de la juventud" (Iciar, 2003: 14) y que "definen el lugar que ocupa el individuo en la sociedad" (Torres y Millán, 2001), tales como: el género, la escolaridad, el estatus socioeconómico, etnia, edad y la región de pertenencia.

\section{Diagrama 1}

Variables que marcan y separan la realidad de la juventud

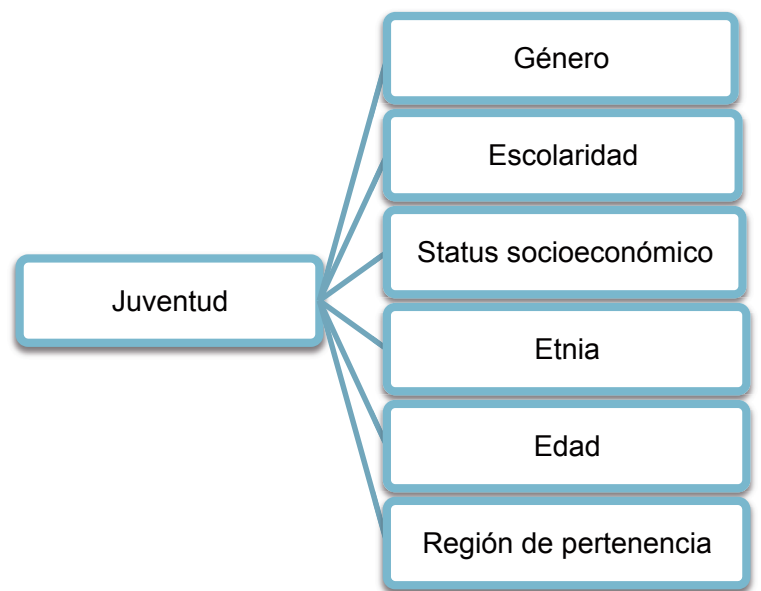

Fuente: Elaboración propia con base en Iciar (2003: 14) y Torres y Millán (2001). 
Según Freixas (1998), citado por Torres y Millán (2001), "para que exista la juventud, deben existir, por una parte, una serie de condiciones sociales (es decir, normas, comportamientos e instituciones que distingan a los jóvenes de otros grupos de edad) y, por otra parte, una serie de imágenes culturales, es decir, valores, atributos y ritos asociados específicamente a los jóvenes".

Desde la perspectiva de Iciar (2003: 18), existen tres tipos de instituciones que determinan lo juvenil: un primer grupo son las instituciones de socialización (escuela, comunidad, etc.); un segundo grupo, "bienes simbólicos, culturales y de consumo, las empresas productoras de estos y el imaginario construido en torno a ellos"; y como tercer grupo, las "normas y aparatos jurídicos y políticos que definen el estatus de la juventud en un determinado momento y lugar".

Por otro lado, desde el punto de vista del desarrollo biopsicosocial, el inicio de la juventud se asocia a la pubertad y adolescencia, con todos los cambios psicológicos y hormonales que dicho proceso conlleva, tales como: la identificación sexual y el desarrollo de las características sexuales, la búsqueda de la autonomía e independencia, el cambio de la importancia en los grupos de referencia (pasando de una primacía de la familia a la del grupo de pares), así como el diseño de proyectos personales de vida, entre otros rasgos definitorios ( $\mathrm{Na}$ ciones Unidas, 2008).

Desde una perspectiva biológica, se encuentran definiciones de la juventud a partir de ciertos rangos de edad. Así según Rodríguez (2001) -citado por Naciones Unidas (2008)-, desde 1985 las Naciones Unidas adoptaron como criterio normativo el grupo etario que se encuentra entre 15 y 24 años, el cual puede desplazarse hacia arriba o hacia abajo, según las exigencias que impongan los contextos particulares -y nacionales- a los jóvenes. En Europa, debido sobre todo a la prolongación de la escolaridad y la postergación de la edad de formación de familias propias, el criterio que se ha establecido es entre 15 y 29 años.

En general, cuando se define el rango de edad que delimita la juventud, el enfoque fija en la cota inferior la edad en que ya están desarrolladas las funciones sexuales y reproductivas y la cota superior en el cierre del proceso educativo formal, el ingreso al mercado de trabajo y la formación del hogar propio.

\subsection{Perspectiva legal en El Salvador}

En El Salvador, existe una legislación ${ }^{1}$ relacionada con la juventud, la cual se puede encontrar en orden de importancia de la siguiente manera: 1. Constitución de la República; 2. tratados internacionales; 3. 
leyes secundarias; 4. Reglamentos. Otra división de los cuerpos normativos que regulan la edad en El Salvador se realiza dependiendo del tema a tratar; por ejemplo, el artículo 26 del Código Civil se refiere a las relaciones de carácter civil como contratos, para efectos de realizar negocios y testamentos, entre otros actos. El artículo reza de la siguiente manera:

Llámase [sic] infante todo el que no ha cumplido siete años; impúber, el varón que no ha cumplido catorce años y la mujer que no ha cumplido doce años; menor adulto, el que ha dejado de ser impúber; mayor de edad, o simplemente mayor, el que ha cumplido dieciocho años; y menor de edad o simplemente menor el que no ha llegado a cumplirlos.

La Ley de Protección Integral de la Niñez y Adolescencia (LEPINA) tiene como ámbito de aplicación los derechos y protección de los niños, especialmente en las relaciones familiares. En su artículo 3 define como "niño" a toda aquella persona desde el instante mismo de la concepción hasta antes de cumplir 12 años, y "adolescente" desde los 12 hasta antes de cumplir 18 años.

Por otra parte, la Ley General de Juventud, en su artículo 2, define al joven como "la persona comprendida en el rango de edad de los 15 a los 29 años, sin distinción de nacionalidad, etnia, género, religión, discapacidad, situaciones de vulnerabilidad o cualquier otra condición particular". Esto implicaría armonizar las leyes citadas; sin embargo, el segundo inciso de este mismo artículo facilita esta tarea al indicar que la definición de joven "no sustituye los límites establecidos en otras leyes, tratados o acuerdos internacionales ratificados por El Salvador, en los que se establecen garantías y responsabilidades civiles o penales y sistemas especiales de protección de derechos ciudadanos" para las personas comprendidas en este rango.

Tomando en cuenta lo que plantea la Ley General de Juventud, para este estudio se tomará como jóvenes el rango comprendido entre los 15 y 29 años; sin embargo, para el análisis de variables del mercado de trabajo, la cota inferior será de 16 años, $^{2}$ a partir de la consideración de la Dirección General de Estadística y Censos (DIGESTYC) de la edad mínima para incorporarse al mercado de trabajo.

Si bien es cierto existen diferencias entre los grupos etarios que se pueden catalogar como jóvenes, para minimizar los efectos que pudiera tener la homogenización a través de la edad, se planteará 
el análisis a través de subgrupos de edad dentro de los jóvenes. De esta manera, para el estudio de las condiciones laborales, el grupo etario se dividirá en tres: el primero, de 16 a 19 años; el segundo de 20 a 24 años; y el tercero de 25 a 29 años. Asimismo, es importante señalar que quienes tengan 30 años o más, se les llamará adultos en este artículo.

\section{Legislación y calidad de empleo}

\subsection{El salario}

La relación laboral se genera por medio de un contrato que tiene como uno de sus principales componentes la remuneración que recibe la persona que presta sus servicios. Dicha remuneración recibe el nombre técnico-jurídico de "salario". En este sentido, se expresan Marcucci (2005: 67), Sabogal (2012: 161) y Cabanellas (2001: 611-612).

El salario lo define Marcucci (2005: 67) como "la contraprestación recibida por el trabajador a cambio de su esfuerzo, de su actividad personal o profesional encaminada a la producción, que encuentra su origen o causa jurídica en el mismo contrato de trabajo". Por su parte, Sabogal (2012: 161) presenta una definición más breve: "Es la contraprestación económica que recibe el trabajador por la prestación de sus servicios". Una tercera definición expresa que el salario es "el conjunto de ventajas materiales que el trabajador obtiene como remuneración del trabajo que presta en una relación subordinada laboral" (Cabanellas, 2001: 608).

En El Salvador, el salario es, según el artículo 119 del Código de Trabajo, "la retribución en dinero que el patrono está obligado a pagar al trabajador por los servicios que le presta en virtud de un contrato de trabajo". Sin embargo, estas definiciones no son suficientes para aclarar lo que significa el salario, y por tal motivo continúa el artículo 119 explicando lo siguiente:

Considérase [sic] integrante del salario, todo lo que recibe el trabajador en dinero y que implique retribución de servicios, cualquiera que sea la forma o denominación que se adopte, como los sobresueldos y bonificaciones habituales; remuneración del trabajo extraordinario, remuneración del trabajo en días de descanso semanal o de asueto, participación de utilidades. 
El salario es considerado "una función social, goza de la protección del Estado, y no se considera artículo de comercio", según el artículo 37 de la Constitución de la República. Lo anterior implica que el legislador salvadoreño ha reconocido la importancia de regular jurídicamente ciertos aspectos relacionados con el contrato laboral; es decir, mantener derechos mínimos a favor de los trabajadores, los cuales no pueden ser renunciados por estos, incluso si están de acuerdo las partes y lo establecen por escrito.

Una de las razones es que una gran mayoría no puede subsistir de forma independiente, por lo que se encuentran en la necesidad de establecer relaciones con otras personas donde se intercambia dinero a cambio de trabajo; en segundo lugar, si se permitiera libremente a las partes fijar el precio del trabajo (como si se tratara de un bien), entonces el empleador tendría una considerable ventaja al momento de negociar el salario e indudablemente se podría llegar al abuso; $y$, en tercer lugar, al no haber una regulación legal se violentaría el principio de "igual trabajo, igual salario" que regulan el artículo $38\left(n^{\circ} 1\right)$ y 3 de la Constitución, ambos relacionados con el artículo 123 del Código de Trabajo, ya que dependería de la negociación entre el futuro trabajador y el posible empleador.

Debido al objeto de estudio del presente artículo, solamente se analizará una de las características o propiedades del salario, para después examinar jurídicamente la situación laboral de los jóvenes en El Salvador. La característica seleccionada, aplicada en El Salvador, consiste en que el salario deberá ser pagado en moneda de curso legal, según el artículo 38 ( $\left.n^{\circ} 4\right)$ de la Constitución y el artículo 120 del Código de Trabajo, lo cual quiere decir que no puede entregar el patrono o empleador, en concepto de remuneración, especies (por ejemplo: boletos para comprar comida, bienes que elabora la empresa, como televisores, teléfonos, comida, etc.) ni divisas que no sean colones salvadoreños o dólares americanos (por ejemplo: pesos colombianos, lempiras, quetzales, etc.).

Respecto del pago en especie, se puede considerar como una forma de limitar la libertad del trabajador de adquirir bienes o servicios, visto que, al no tener dinero, no podría comprar lo que éste considera necesario, y además esto permitiría un abuso de parte de los empleadores, ya que ellos decidirían el salario tomando como base sus productos, puesto que sería imposible regular cuánto en verdad recibe el trabajador y la forma de determinar el valor del artículo entregado. La razón de exigir moneda de curso legal es con la intención de que el trabajador pueda hacer uso inmediato del dinero y prevenir que se disminuya en forma real su salario al realizar la conversión de 
divisas. Sin embargo, existen países como Argentina ${ }^{3}$ y Colombia ${ }^{4}$ en donde es posible pagar cierta parte del salario en especie.

Antes de hablar sobre el salario mínimo es necesario aclarar que durante la etapa final de esta investigación, el presidente de la República reformó el salario mínimo según los decretos del Órgano Ejecutivo número 103, 104, 105 y 106 del día 1 de julio de 2013. Sin embargo, no han aparecido publicados hasta el momento en el Diario Oficial. ${ }^{5}$ Dichos decretos separan los salarios en cuatro grandes rubros dependiendo del tipo de trabajo: 1 . trabajadores agropecuarios, 2. trabajadores de recolección de cosechas de café, algodón y caña de azúcar, 3. trabajadores del comercio y servicios, industria, maquila textil y confección y 4. trabajadores de las industrias agrícolas de temporada.

Estos decretos incrementará el salario mínimo en un $12 \%$, pero tiene la característica de ser un aumento paulatino de tres tramos del $4 \%$ en cada una en las siguientes fechas: 1 de julio de 2013, 1 de enero de 2014 y 1 de enero de 2015.

Tabla 1

Salarios mínimos del año 2013 de trabajadores contratados por unidad de tiempo

\begin{tabular}{|c|c|c|c|}
\hline RUBROS & $01 / 07 / 2013$ & 01/01/2014 & $01 / 01 / 2015$ \\
\hline \multicolumn{4}{|c|}{ Trabajadores de las industrias agrícolas de temporada } \\
\hline Beneficios de café & US\$5.27 & US\$5.48 & US\$5.70 \\
\hline Beneficios de algodón e ingenios de caña de azúcar & US\$3.83 & US\$3.98 & US\$4.14 \\
\hline \multicolumn{4}{|c|}{ Trabajadores de recolección de cosechas de café, algodón y caña de azúcar } \\
\hline Recolección de café & US\$3.97 & US\$4.13 & US\$4.30 \\
\hline Recolección de algodón & US\$3.04 & US\$3.16 & US\$3.29 \\
\hline Recolección de caña de azúcar & US\$3.37 & US\$3.50 & US\$3.64 \\
\hline \multicolumn{4}{|c|}{ Trabajadores del comercio y servicios, industria, maquila textil y confección } \\
\hline Trabajadores del comercio y servicios & US\$7.77 & US\$8.08 & US\$8.39 \\
\hline Trabajadores de la industria & US\$7.60 & US\$7.90 & US\$8.22 \\
\hline Trabajadores de la maquila textil y confección & US\$6.50 & US\$6.76 & US\$7.03 \\
\hline \multicolumn{4}{|c|}{ Trabajadores agropecuarios } \\
\hline & US\$3.64 & US\$3.79 & US\$3.94 \\
\hline
\end{tabular}

Fuente: Elaboración propia con base en los decretos ejecutivos 103, 104, 105 y 106 del 1 de julio de 2013. 
Otro punto importante sobre este evento, y que afecta significativamente el análisis jurídico del caso de estudio que se desarrollará más adelante, es que los salarios han aumentado y esto provocaría en principio un incumplimiento de la ley por parte de los empleadores, porque los contratos y reglamentos estudiados tienen en consideración los mínimos vigentes de la época en la cual se firman, por lo que sería irrazonable evaluar un contrato laboral firmado con una ley nueva; sin embargo, se hace la acotación de que en caso un salario estipula- do en un contrato sea inferior al mínimo vigente de su respectivo rubro, prevalece la ley sobre la voluntad de las partes, por lo que se deberá pagar el salario mínimo estipulado por la ley vigente.

Para efectos del análisis jurídico de los casos de estudio, se tomarán en cuenta los salarios mínimos del 6 de mayo de 2011, desarrollados por medio de los decretos del Órgano Ejecutivo número 54, 55, 56 y 57 y publicados ese mismo día en el Diario Oficial número 85, tomo 391.

\section{Tabla 2}

\section{Salarios mínimos del año 2011 de trabajadores contratados por unidad de tiempo}

\begin{tabular}{|c|c|}
\hline RUBROS & CANTIDAD \\
\hline \multicolumn{2}{|c|}{ Trabajadores de las industrias agrícolas de temporada } \\
\hline Beneficios de café & US\$5.07 \\
\hline Beneficios de algodón e ingenios de caña de azúcar & US\$3.68 \\
\hline \multicolumn{2}{|c|}{ Trabajadores de recolección de cosechas de café, algodón y caña de azúcar } \\
\hline Recolección de café & US\$3.82 \\
\hline Recolección de algodón & US\$2.92 \\
\hline Recolección de caña de azúcar & US\$3.24 \\
\hline \multicolumn{2}{|c|}{ Trabajadores del comercio y servicios, industria, maquila textil y confección } \\
\hline Trabajadores del comercio y servicios & US\$7.47 \\
\hline Trabajadores de la industria & US\$7.31 \\
\hline Trabajadores de la maquila textil y confección & US\$6.25 \\
\hline \multicolumn{2}{|c|}{ Trabajadores agropecuarios } \\
\hline & US\$3.50 \\
\hline
\end{tabular}

Fuente: Elaboración propia con base en los decretos ejecutivos 54, 55, 56 y 57 del 6 de mayo de 2011.

Anteriormente se analizaron algunas características del salario mínimo, incluyendo las reformas del aumento salarial de 2013; sin embargo, es necesario examinar las condiciones laborales mínimas que 
deben cumplirse en el caso de los jóvenes, lo cual se realizará en el siguiente subapartado.

\subsection{Los jóvenes y el trabajo}

Constitucionalmente, el artículo 38 ( $\left.n^{\circ} 10\right)$ de la Constitución establece restricciones a los menores, ya que prohíbe la contratación laboral de personas menores de 14 años; además, menores que tengan 14 años solo pueden ser contratados si el trabajo "se consider[a] indispensable para la subsistencia de los mismos o de su familia, siempre que ello no les impida cumplir con el mínimo de instrucción obligatoria". Otra limitante es que los menores de 16 años no pueden trabajar más de 6 horas diarias ni 34 horas semanales. Todos los menores de 18 años no pueden realizar trabajos nocturnos ni insalubres. ${ }^{6}$

El artículo 114 del Código de Trabajo, al igual que la Constitución, establece que los menores de 14 años y los que han cumplido esa edad que "sigan sometidos a la enseñanza obligatoria, no podrán ser ocupados en trabajo alguno"; sin embargo, el artículo 115 del Código de Trabajo lleva a una contradicción con el artículo 114 del mismo Código y el artículo 38 ( $\left.n^{\circ} 10\right)$ de la Constitución, visto que expresa que "los menores de catorce años, en el caso del artículo anterior, deberán contratar por medio de sus representantes legales $y$, a falta de éstos, por medio de las personas de quienes dependan económicamente o de la Procuraduría General de Pobres".7

Esto se debe a una mala adaptación de una reforma al Código de Trabajo para que armonizara con la LEPINA. ${ }^{8}$ La LEPINA, en su artículo 59, establece que la edad mínima para realizar actividades laborales es de 14 años, y además establece la siguiente condición: "siempre y cuando se garantice el respeto de sus derechos y no perjudique el acceso y derecho a la educación. Bajo ningún concepto se autorizará el trabajo para las niñas, niños y adolescentes menores de catorce años".

¿En qué consiste la contradicción? El artículo 114 del Código de Trabajo antes establecía que era posible contratar a un niño que haya cumplido los 12 años, ${ }^{9} \mathrm{y}$ hace referencia a dos términos distintos: "menores de 14 años" y "los que habiendo cumplido esa edad". Pero al realizar las adaptaciones correspondientes, no modificó el artículo 115 del mismo, que hace referencia a los "menores de 14 años", por lo que se puede interpretar que un niño que no haya cumplido los 14 años puede ser contratado laboralmente por medio de su representante legal.

Por otro lado, El Salvador ha firmado y ratificado diversos convenios relacionados con el ámbito laboral, y entre estos se encuentra el "Convenio sobre la Edad Míni- 
ma" de 1973 (convenio número 138), que en su artículo 2 establece que una persona menor a la edad mínima no puede ser admitida en un trabajo y ésta deberá ser fijada por el Estado (en este caso por El Salvador), pero que no podrá ser "inferior a la edad en que cesa la obligación escolar, o en todo caso, a quince años". Sin embargo, el mismo convenio establece una excepción ${ }^{10}$ a esta limitante y autoriza, en el caso de países "cuya economía y medios de educación estén insuficientemente desarrollados", la edad mínima de 14 años. Esto concuerda con el artículo 38 ( $\left.n^{\circ} 10\right)$ de la Constitución ${ }^{11}$ y con el artículo 114 del Código de Trabajo, pero en contradicción con el artículo 115 del mismo, por las razones expuestas anteriormente.

Además, el mismo convenio (artículo 3, párrafo 1) establece que en el caso de empleos que sean peligrosos ya sea por la salud, seguridad o moralidad, la edad mínima de admisión será de 18 años, pero hay una excepción de admitir a partir de los 16 años siempre que se garantice lo anterior y "hayan recibido instrucción o formación profesional adecuada y específica en la rama de actividad correspondiente". El artículo 105 del Código de Trabajo $^{12}$ se expresa en este mismo sentido, pero en apariencia existe una contradicción con el artículo 38 ( $n^{\circ} 10$, inciso final) de la Constitución que "prohíbe el trabajo a los menores de dieciocho años y a las mujeres en labores insalubres o peligrosas", pero se solventa al garantizar la seguridad y salud de los menores.

Finalmente, el artículo 6 del Convenio sobre la Edad Mínima aclara que no se aplicará a las personas que por lo menos hayan cumplido 14 años y que sea por medio de organizaciones que se dediquen a la enseñanza, programas de formación o de orientación. El artículo 105 inciso final del Código de Trabajo toma esta posición, ya que las prohibiciones no se aplican en escuelas de enseñanza general, profesional o técnica o en otras instituciones de formación.

Un segundo convenio denominado "Convenio sobre el Examen Médico de los Menores (Industria)" de 1946 (convenio número 77), en su artículo 2, regula la admisión de menores en empresas industriales ya sean públicas o privadas. Esta regulación consiste en que no se admitirán a menores de 18 años a menos que aprueben un minucioso examen médico. Prosigue el mismo artículo con los requisitos para realizarlo, y básicamente son: a) Examen hecho por un médico calificado y reconocido por autoridad competente y b) deberá realizarse dicho examen periódicamente en intervalos que no excedan un año hasta que el empleado cumpla 18 años.

Por último, el artículo del 5 convenio número 77 exige que el 
examen sea gratuito para el trabajador y el artículo 4 establece que si el empleo es un gran riesgo para la salud, el examen médico deberá realizarse periódicamente hasta que el empleado cumpla 21 años. Todos los requisitos mencionados anteriormente se encuentran en armonía con el artículo 117 del Código de Trabajo y los artículos 66 y 68 de la LEPINA.
Finalmente, el artículo 2 del "Convenio sobre las Peores Formas de Trabajo Infantil" de 1999 (convenio número 182) define "niño" a toda persona menor de 18 años. Sin embargo, esto solo se aplica para dicho convenio, y el artículo 3 del mismo ejemplifica que actividades deberán entenderse como "las peores formas de trabajo infantil", siendo estas:

- Todas las formas de esclavitud o las prácticas análogas a la esclavitud, como la venta y el tráfico de niños, la servidumbre por deudas y la condición de siervo, y el trabajo forzoso u obligatorio, incluido el reclutamiento forzoso u obligatorio de niños para utilizarlos en conflictos armados;

- La utilización, el reclutamiento o la oferta de niños para la prostitución, la producción de pornografía o actuaciones pornográficas;

- La utilización, el reclutamiento o la oferta de niños para la realización de actividades ilícitas, en particular la producción y el tráfico de estupefacientes, tal como se definen en los tratados internacionales pertinentes, y

- El trabajo que, por su naturaleza o por las condiciones en que se lleva a cabo, es probable que dañe la salud, la seguridad o la moralidad de los niños.

Hasta el momento se ha tratado el tema del salario y cómo se encuentra regulada la edad mínima para la contratación laboral. El siguiente subtema analizará los mínimos legales que se deberán cumplir en el contrato laboral y las prestaciones sociales.

\subsection{El contrato laboral y los mínimos legales}

Ya se ha explicado lo necesario para entender el tema del salario, pero es de aclarar que existen diversas modalidades para estipularlo y el tiempo para pagarlo. Los artículos 
126 y 130 del Código de Trabajo regulan respectivamente estas situaciones. Las principales formas de

- Por unidad de tiempo: cuando el salario se paga ajustándolo a unidades de tiempo, sin consideración especial al resultado del trabajo.

- Por unidad de obra: cuando sólo se toma en cuenta la cantidad y calidad de obra o trabajo realizado, pagándose por piezas producidas o medidas o conjuntos determinados, independientemente del tiempo invertido.

- Por sistema mixto: cuando se paga de acuerdo con las unidades producidas o trabajo realizado durante la jornada de trabajo.

En el contrato laboral o en el reglamento interno de trabajo usualmente se fija la fecha para el pago del salario, debiendo respetarse las siguientes fecha que estipula el artículo 130 del Código de Trabajo:

- Si se hubiere estipulado por unidad de tiempo, al vencimiento del período correspondiente, como semana, quincena, mes o el día hábil inmediato anterior;

- Si se hubiere estipulado por unidad de obra, sistema mixto, por tarea, o a destajo, dentro de los dos días siguientes al de la entrega o recuento respectivo; y

- Si se hubiere estipulado por comisión, al ser liquidada, operación esta que hará la empresa en forma individual o general, por lo menos cada quince días. Al mismo tiempo deberá pagarse el salario fijo [...]

- En circunstancias especiales, calificadas previamente por el Director General de Trabajo, los plazos a que se refiere este artículo podrán ampliarse sin que esta ampliación pueda exceder de seis días.

Otro punto importante del contrato laboral es la jornada, siendo éstas de dos tipos: jornada diurna y jornada nocturna. La Constitución, en su artículo $38\left(n^{\circ} 6\right)$, regula la primera estableciendo que "no ex- 
cederá de ocho horas [diarias] y la semana laboral de cuarenta y cuatro horas". El artículo 161 del Código de Trabajo, por su parte, retoma lo anterior y regula la jornada nocturna, la cual no será mayor a siete horas diarias ni treinta y nueve horas semanales; y en el mismo artículo 161 define qué horas abarca cada jornada: "Las diurnas están comprendidas entre las seis horas y las diecinueve horas de un mismo día; y las nocturnas, entre las diecinueve horas de un día y las seis horas del día siguiente". Esto plantea una interrogante de carácter práctico: ¿qué clase de jornada será la de una persona que entra a las dieciséis horas? Esto es importante porque afecta la duración de la jornada laboral y para efectos del salario, y la respuesta la ofrece el mismo artículo 161: "La jornada de trabajo que comprenda más de cuatro horas nocturnas, será considerada nocturna para el efecto de su duración". En este caso, se entenderá que la jornada es nocturna $y$, por tanto, durará siete horas.

Esta es la regla general, pero cuando se involucran factores de peligro o de riesgo en el trabajo, el artículo 162 del Código de Trabajo las reduce de la siguiente forma:

- Jornada diurna: 7 horas diarias y 39 horas semanales.

- Jornada nocturna: 6 horas diarias y 36 horas semanales.

- Si la jornada comprende más de tres y media horas nocturnas, será considerada nocturna, para los efectos de su duración.

No está de más señalar que cuando se trata de personas que hayan cumplido 14 años y antes de cumplir los 18 años, se someten a otras reglas $y$, entre éstas, se les prohíbe realizar jornadas nocturnas, tareas insalubres o peligrosas (como se explicó anteriormente) y trabajar más de 6 horas diarias y 34 horas semanales.

Puede darse la situación de que en un principio se haya estipulado un horario específico y que posteriormente se modifique, por lo que en el segundo caso se deberá llegar a un acuerdo con el trabajador, mientras que en el primero lo decide el patrono. Todo lo anterior según el artículo 165 del Código de Trabajo.

Aparte de la duración entre ambas jornadas, ¿qué otra diferencia existe entre la jornada diurna y nocturna? La hora nocturna se pagará, por lo menos, con un $25 \%$ más de lo que correspondería a las horas diurnas; es decir, que si la hora diurna es de US\$10.00, entonces 
la hora en jornada nocturna será de US\$12.25, según el artículo 168 del mismo Código.

Otro uso importante de establecer el horario es que de esa forma se pueden determinar las horas extra y, según el artículo 169 del Código, se pagarán con el 100\% adicional del salario básico por hora. Un ejemplo sería el siguiente: Sandra gana US\$10.00 por hora y trabaja una hora adicional en la jornada diurna, por lo que ésta deberá ser remunerada con US\$20.00 y, en caso de ser jornada nocturna, será de $\$ 25.00$ porque el $100 \%$ se aplica sobre $\$ 12.50$. Ese trabajo debe ser verificado y de ahí la importancia de llevar control de ingreso y de salida para los trabajadores.

El descanso semanal es otro aspecto importante del contrato laboral, y se encuentra regulado en los artículos 171 al 176 del Código de Trabajo. Este descanso semanal consiste en un día remunerado (artículo 171) y por regla general es el domingo (artículo 173), pero se puede modificar en caso de tratarse de empresas de trabajo continuo, las que presten un servicio público o que laboren normalmente ese día. En estas situaciones, se requiere la autorización del director general de Trabajo para seleccionar otro día. La remuneración del día de descanso es el equivalente al salario de un día completo (artículo 174) y si se estipula el pago por semana, quincena, mes u otro período mayor, se presume que va incluida esta remuneración. En el caso de que un empleado trabaje el día en el cual le corresponde descansar, entonces tendrá derecho a (artículos 175 y 176):

- El salario básico más un 50\% sobre las horas que trabaje.

- Un día de descanso compensatorio remunerado de la misma forma que el día de descanso semanal.

Por ejemplo, Raúl trabajará el domingo y su salario básico por día es de US\$80.00, siendo US\$10.00 por hora. Entonces si trabaja 9 horas (una hora extra) serían: US\$80.00 por salario básico, más US $\$ 40.00$ por el $50 \%$ adicional y US\$30.00 por la hora extra, dando un total de US\$150.00.

Otra prestación importante para el trabajador es la vacación anual remunerada, la cual se regula desde el artículo 177 al 189 del Código de Trabajo. Un trabajador tiene derecho a la misma si ha trabajado por lo menos un año (artículo 177) y consistirán en 15 días remunerados con el salario ordinario con un $30 \%$ adicional. Por ejemplo: José tiene un salario por día de US\$80.00, por tanto, la remuneración por sus vacaciones serán de US\$1,560.00 (US\$1,200.00 de salario ordinario 
más US $\$ 360.00$ por el $30 \%$ adicional). Los días de descanso y asueto se encuentran incluidos en ese lapso de 15 días, pero no pueden iniciar en esos días las vacaciones anuales (artículo 178). Además, el pago de estas deberá hacerse antes de iniciar las mismas y de forma completa (artículo 185). En caso de que el trabajador sea despedido sin causa legal o con responsabilidad para el patrono antes de que complete un año de servicio, entonces las vacaciones se pagarán de forma proporcional al tiempo de trabajo (artículo 187). Continúa explicando el mismo artículo que en caso de tener ya un año de servicio cumplido, y si es despedido, incluso sin responsabilidad para el patrono, éste deberá pagarle las vacaciones.

Por su parte, el artículo 188 del Código de Trabajo establece una serie de restricciones que incluyen la prohibición de compensar en dinero o especie y fraccionar o acumular los períodos de vacaciones, además -continúa el artículo- de que es una obligación del patrono darlas y del trabajador tomarlas. Relacionado con la acción de fraccionar las vacaciones, el artículo 189 , inciso 2 , permite que, de común acuerdo con la mayoría de trabajadores, fraccionarlas en dos o más períodos en el año con las restricciones siguientes: si son dos períodos, entonces cada uno tendrá que durar 10 días y si son tres, cada uno durará 7 días.

Finalmente, el tema relacionado con las prestaciones laborales es el aguinaldo. El aguinaldo es una prima que entrega el patrono al trabajador, es decir, una cantidad de dinero (artículo 196). Cuando el trabajador tenga un año o más de servicio (artículo 197, inciso 1). En caso de que el trabajador no hubiera completado un año al 12 de diciembre, se le pagará de forma proporcional (artículo 197 inciso 2). Por ejemplo: David comenzó a trabajar el 1 de enero de 2013, pero al 12 de diciembre no tiene un año, por lo que se le pagará proporcionalmente. En la medida en que un trabajador sigue trabajando para el mismo patrono, la cantidad del aguinaldo aumenta de la siguiente forma (artículo 198):

- De 1 año a menos de 3 años: 10 días de salario.

- De 3 años a menos de 10 años: 15 días de salario.

- De 10 años en adelante: 18 días de salario.

El aguinaldo se deberá pagar entre el 12 y el 20 de diciembre (artículo 200), de ahí que el artícu- lo 197, inciso 2, establezca que la fecha límite para calcular el año sea el 12 de diciembre. Otra situación 
importante a considerar de esta fecha es que el trabajador puede perderlo si tiene en dos meses (consecutivos o no) más de dos ausencias injustificadas en cada uno (artículo 201). Por ejemplo: José, en enero, se ha ausentado injustificadamente 3 veces y en octubre 3 veces más, por lo que cumple con lo establecido en el artículo y perderá su aguinaldo. En caso de despido sin causa legal o con responsabilidad para el patrono, éste se encuentra en la obligación de pagar proporcionalmente el aguinaldo (artículo 202).

Existen dos obligaciones, para empleados y patronos, que consisten en cotizar en las instituciones Administradoras de Fondos de Pensiones (AFP) y en el Instituto Salvadoreño del Seguro Social (ISSS). La primera se encuentra regulada por la Ley del Sistema de Ahorro para Pensiones, y en su artículo 1 establece que abarca a "los trabajadores del sector privado, público y municipal" y el artículo 7 señala que la afiliación "será obligatoria cuando una persona ingrese a un trabajo en relación de subordinación laboral". Respecto del ISSS, el artículo 3 de la Ley del Seguro Social establece que será obligatorio y "se aplicará originalmente a todos los trabajadores que dependan de un patrono sea cual fuere el tipo de relación laboral que los vincule y la forma que los haya establecido la remuneración". Estas cotizaciones implican descontar del salario del trabajador cierta cantidad de dinero y el patrono deberá aportar, de igual manera, otra cantidad, siendo los porcentajes actuales los presentados en la tabla 3.

Tabla 3

Porcentajes de cotizaciones

\begin{tabular}{|l|c|c|c|}
\hline \multicolumn{1}{|c|}{ Institución } & Trabajador & Patrono & Porcentaje Total \\
\hline ISSS $^{13}$ & $3.0 \%$ & $7.5 \%$ & $10.5 \%$ \\
\hline AFP $^{14}$ & $6.25 \%$ & $6.75 \%$ & $13 \%$ \\
\hline
\end{tabular}

Fuente: Elaboración propia con base en el Reglamento para la Aplicación del Régimen del Seguro Social y la Ley del Sistema de Ahorro para Pensiones.

Se presenta el siguiente ejemplo aplicando las cotizaciones de ambas instituciones para ilustrar mejor la situación: un trabajador gana US\$300.00 mensuales, por lo que deberá descontarse de su salario el $3.0 \%$ para el ISSS y el $6.25 \%$ para la AFP. Esto implica que a los US\$300.00 se retienen US\$9.00
(ISSS) más US\$18.75 (AFP), dejando un salario líquido de US\$272.25. Por su parte, el patrono deberá pagar $7.5 \%$ para el ISSS (US\$22.50) y $6.75 \%$ para la AFP (US\$20.25), haciendo un total de US\$42.75.

Con esto finaliza el análisis legal del salario, las principales 
prestaciones laborales y de otras obligaciones mínimas que tienen por objetivo el beneficio del trabajador. A continuación, se realizará una panorámica general desde el punto de vista económico sobre la situación de los jóvenes en el mercado de trabajo.

\section{Panorama general de la situación de los jóvenes en el mercado laboral}

En El Salvador, así como en otros países de América Latina, la mayor parte de la población está en los grupos etarios de 0 a 29 años de edad (niños y jóvenes), lo que se puede observar en la figura 1. En el período 2007-2012, en promedio este grupo etario representó aproximadamente el 59\%, del cual el $27 \%$ eran jóvenes parte de la Población en Edad de Trabajar (PET). Esto es importante de cara a las políticas relacionadas con la niñez y la juventud por su impacto a nivel social y económico.

\section{Figura 1}

Población por grupos etarios. 2007 a 2012. Total país

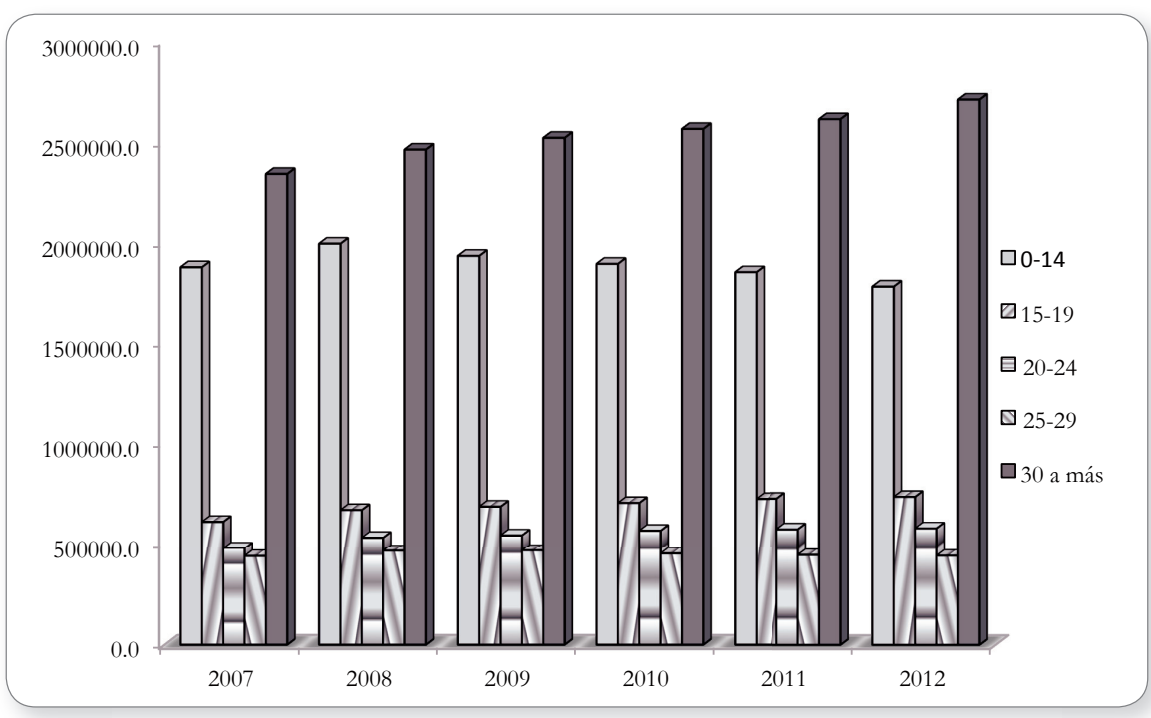

Fuente: Elaboración propia con base en Encuesta de Hogares de Propósitos Múltiples del período 2007-2012. 
Cuando se observa la situación ocupacional de los jóvenes (ver tabla 4), se nota que los grupos ocupacionales en los que están trabajando más jóvenes son: "cuenta propia", "familiar no remunerado", "asalariado permanente" y "asalariado temporal", situación ligeramente distinta a la de los adultos quienes se ubican en grupos ocupacionales de mayor toma de decisiones e ingresos como "patrono".

\section{Tabla 4}

\section{Ocupados por categoría ocupacional. 2007 a 2012. Total país}

\begin{tabular}{|c|c|c|c|c|c|c|c|c|c|c|}
\hline Año & Edad & Patrono & $\begin{array}{l}\text { Cuenta } \\
\text { propia }\end{array}$ & Cooperat. & $\begin{array}{c}\text { Familiar no } \\
\text { remune. }\end{array}$ & $\begin{array}{l}\text { Asalariado } \\
\text { permanen. }\end{array}$ & $\begin{array}{c}\text { Asalariado } \\
\text { temporal }\end{array}$ & Aprendiz & $\begin{array}{l}\text { Servicio } \\
\text { doméstico }\end{array}$ & Otros \\
\hline \multirow{2}{*}{ Д్ని } & $16-29$ & 9,300 & 83,666 & 0 & 90,699 & 319,398 & 175,933 & 4,047 & 34,543 & 681 \\
\hline & 30 a más & 89,277 & 533,943 & 327 & 54,236 & 520,535 & 186,911 & 0 & 66,470 & 3,997 \\
\hline \multirow{2}{*}{ ఫ్సి } & $16-29$ & 10,355 & 109,821 & 132 & 104,718 & 362,713 & 162,548 & 4,315 & 41,353 & 1,939 \\
\hline & 30 a más & 92,309 & 581,510 & 245 & 53,363 & 563,070 & 188,392 & 127 & 66,998 & 5,142 \\
\hline \multirow{2}{*}{ ఫ్సి } & $16-29$ & 8,577 & 124,973 & 0 & 114,987 & 319,579 & 174,698 & 3,925 & 41,592 & 490 \\
\hline & 30 a más & 93,572 & 611,100 & 257 & 54,184 & 557,810 & 188,040 & 80 & 70,353 & 362 \\
\hline \multirow{2}{*}{ 을 } & $16-29$ & 11,602 & 120,489 & 53 & 106,623 & 318,343 & 187,369 & 3,473 & 32,975 & 129 \\
\hline & 30 a más & 86,983 & 615,494 & 0 & 60,902 & 567,326 & 220,796 & 339 & 65,507 & 75 \\
\hline \multirow{2}{*}{$\overline{\bar{ন}}$} & $16-29$ & 9,552 & 116,882 & 0 & 120,337 & 47 & 196,106 & 3,574 & 2,046 & 390 \\
\hline & 30 a más & 82,577 & 634,320 & 0 & 63,986 & 589,627 & 218,644 & 112 & 70,262 & 113 \\
\hline \multirow{2}{*}{ స్తి } & $16-29$ & 9,977 & 113,931 & 0 & 129,055 & 331,000 & 186,711 & 4,513 & 35,558 & 537 \\
\hline & 30 a más & 98,229 & 648,386 & 0 & 69,058 & 639,711 & 215,521 & 245 & 76,222 & 661 \\
\hline
\end{tabular}

Fuente: Elaboración propia con base en Encuesta de Hogares de Propósitos Múltiples de 2007 a 2012.

En El Salvador las tres ramas económicas en las que se encontraron más ocupados tanto jóvenes como adultos, en el período 20072012, son: "agricultura, ganadería, caza y silvicultura", "industria manufacturera" y "comercio, hoteles y restaurantes". Todas ellas se caracterizan por remuneraciones bajas, sobre todo si se toma en cuenta que apenas alcanzan a cubrir la Canasta
Básica Alimentaria Ampliada Rural (CBAAR), y en los casos más extremos no se cubre la Canasta Básica Alimentaria Ampliada Urbana (CBA$\mathrm{AU})$. Asimismo, presentan tasas de crecimiento promedio ${ }^{15}$ reducidas en dicho período. Así, la "industria manufacturera" de $1.15 \%$, "agricultura, ganadería, caza y silvicultura" con $0.67 \%$ y "comercio, hoteles y restaurantes" con $0.2 \%$. 
Aunado a lo anterior, cuando se observa la situación por grupos de edad, se evidencia que, en promedio, los salarios que reciben los jóvenes son menores a los de los adultos $y$, por tanto, tienen más dificultades para satisfacer sus necesidades de "Ser, Tener, Hacer, Estar [...] Protección, Afecto, Entendimiento, Participación, Ocio, Creación, Identidad y Libertad" (Max-Neef, 1993: 41).

\section{Tabla 5}

Salarios promedio por grupos de edad. 2007 a 2012. Total país

\begin{tabular}{|l|r|r|r|r|r|r|}
\hline \begin{tabular}{l} 
Año \\
\hdashline Edad
\end{tabular} & $\mathbf{2 0 0 7}$ & $\mathbf{2 0 0 8}$ & $\mathbf{2 0 0 9}$ & $\mathbf{2 0 1 0}$ & $\mathbf{2 0 1 1}$ & $\mathbf{2 0 1 2}$ \\
\hline $\mathbf{1 6 - 1 9}$ & 94.51 & 94.11 & 82.78 & 88.16 & 89.64 & 82.92 \\
\hline $\mathbf{2 0 - 2 4}$ & 167.17 & 175.27 & 147.98 & 173.58 & 170.61 & 172.62 \\
\hdashline $\mathbf{2 5 - 2 9}$ & 222.34 & 228.35 & 215.04 & 230.92 & 225.71 & 233.61 \\
\hdashline $\mathbf{3 0}$ a más & 264.36 & 280.19 & 258.73 & 259.91 & 256.74 & 263.98 \\
\hline
\end{tabular}

Fuente: Elaboración propia a partir de las bases de datos ${ }^{16}$ de Encuesta de Hogares de Propósitos Múltiples de 2007 a 2012.

Un indicador de la situación laboral en un país es la tasa de desempleo; así, en la figura 2 se muestran las tasas de desempleo nacional, juvenil ${ }^{17}$ y de adultos, que permite observar que el desempleo en los jóvenes es mayor que el de adultos. Algunos de los factores que podrían estar influyendo en esta situación son:

a. Una parte de estos jóvenes se encuentran bajo la "moratoria social", que "alude a un plazo concedido a cierta clase de jóvenes, que les permite gozar de una menor exigencia mientras completan su instrucción y alcanzan su madurez social y económica" (Magulis, 2013: 43).

b. La valoración por parte de los empleadores de la experiencia por encima de la preparación académica, lo que lleva a que generalmente personas de mayor edad tengan más experiencia y sean contratados. 
Figura 2

Tasas de desempleo nacional, juvenil y de adultos. 2007 a 2012. Total país

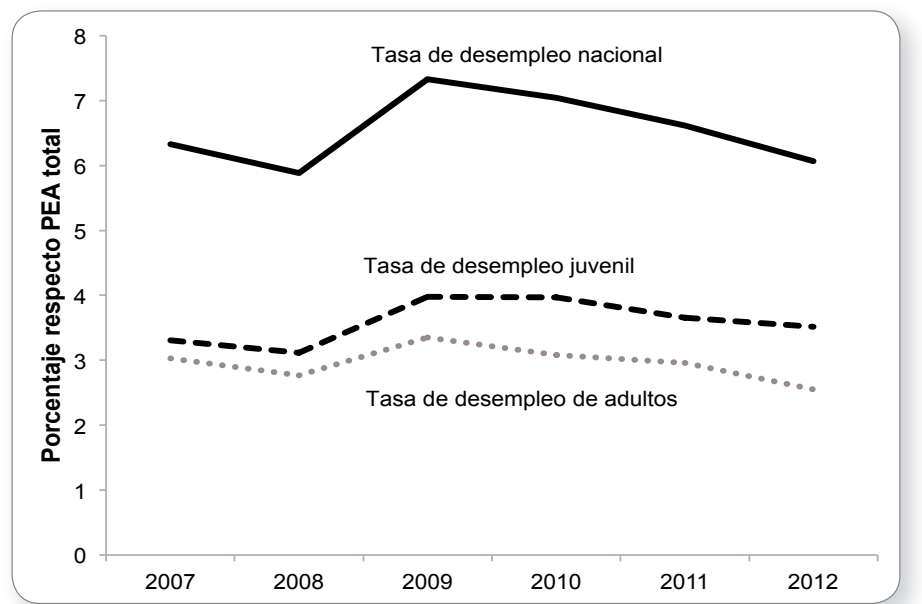

Fuente: Elaboración propia con base en Encuesta de Hogares de Propósitos Múltiples del período 2007-2012.

Por otro lado, si se compara la situación del desempleo juvenil de hombres y mujeres, se observa en la figura 3 que los hombres se ven más afectados. Esto podría deberse a que las mujeres se dedican a actividades dentro del sector informal y de subempleo.

\section{Figura 3}

\section{Tasas de desempleo juvenil total, de hombres y mujeres. 2007 a 2012. Total país}

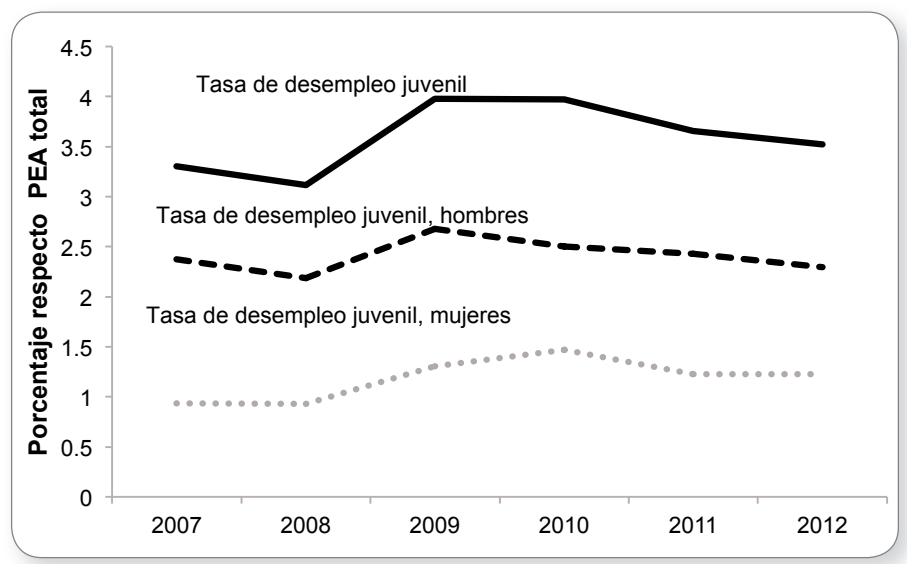

Fuente: Elaboración propia con base en Encuesta de Hogares de Propósitos Múltiples del período 2007-2012. 


$\begin{array}{ll}\text { 4. Caso de estudio: Los call centers en El Salvador } \\ \text { Se ha estudiado hasta el mo- } & \text { Ilaman, Ilamar a terceras personas } \\ \text { nento la parte normativa y eco- } & \text { para ofrecerlos, etc. } \\ \text { necesario contrastar lo anterior con } & \text { era necesario conocer el mecanis- } \\ \text { una situación en concreto, y se ha } & \text { mo de trabajo y la relación patrono- } \\ \text { seleccionado como caso de estudio } & \text { laboral de esta clase de empresas, } \\ \text { los call centers. Los call centers son } & \text { por lo que se solicitó, el } 15 \text { de ene- } \\ \text { centros de llamada cuya principal } & \text { ro de 2013, a la Oficina de Infor- } \\ \text { función es dar un servicio telefó- } & \text { mación y Respuesta del Ministerio } \\ \text { nico a sus clientes, y éstos pue- } & \text { de Trabajo copias de los contratos } \\ \text { den ser de diversa naturaleza, por } & \text { laborales y reglamentos internos de } \\ \text { ejemplo: proveer soporte técnico, } & \text { trabajo, obteniendo respuesta favo- } \\ \text { dar información sobre productos } & \text { rable el día } 25 \text { de enero de } 2013^{18} \\ \text { o servicios a las personas que les } & \text { con la siguiente información: }\end{array}$

- $\quad$ Tres contratos laborales ${ }^{19}$ de:

Stream

Digitex

Transactel

- Cuatro reglamentos internos de trabajo de:

Dell

Sykes

Atento

Transactel

Debido a que solo hay una copia de contrato laboral que coincide con el reglamento interno de trabajo, específicamente el caso de Transactel, se realizará el análisis comparativo del mismo y posteriormente se estudiarán por separado tanto los contratos laborales como los reglamentos internos de trabajo de las demás compañías. Todo lo anterior, a la luz de las leyes y de la situación económica actual.

\section{Transactel}

El contrato está firmado por un trabajador de 24 años de edad que desempeñará el cargo de asesor telefónico y está sometido tanto al contrato como al reglamento interno de trabajo. Entre sus funciones está estipulada la de brindar servicio al cliente vía telefónica o por correo electrónico. 
El contrato es de duración indefinida. No se había estudiado anteriormente en esta investigación la situación del trabajo temporal o permanente en la legislación salvadoreña. Según el artículo 25 del Código de Trabajo, los trabajos "que por su naturaleza sean perma- nentes en la empresa se consideran celebrados por tiempo indefinido, aunque en ellos se señale plazo para su terminación". Solo hay dos casos excepcionales que admite el mismo artículo para los trabajos temporales:

a) Cuando por las circunstancias objetivas que motivaron el contrato, las labores a realizarse puedan ser calificadas de transitorias, temporales o eventuales; y

\section{b) Siempre que para contratar se hayan tomado en cuenta circunstancias o acontecimientos que traigan como con- secuencia la terminación total o parcial de las labores, de manera integral o sucesivas.}

En otras palabras, la regla general es el contrato de tiempo indefinido y la excepción es el contrato temporal. La clave para determinar si un contrato es temporal o permanente es la siguiente: se debe considerar si la función realizada por la persona es indispensable para el rubro que realiza la compañía, por ejemplo: las funciones de una secretaria son necesarias para todo tipo de compañías, por lo que se considera como función permanente.

Ahora bien, tomemos un segundo ejemplo: las funciones de un docente son indispensables en una institución de educación, por lo que el trabajo es de carácter indefinido, pero si se intenta colocar esta misma función en una compañía que no se dedique a la educación, sino que capacite esporádicamente a sus empleados, entonces el contrato es temporal porque la función no es indispensable para la compañía.

En resumen, es de analizar los casos en concreto para determinar qué tipo de contrato aplica. Ejemplos de contratos temporales serían las personas que se dedican a recoger la cosecha de la caña de azúcar, maíz, etc., ya que son por temporadas.

La Sala de lo Civil de la Corte Suprema de Justicia de El Salvador ha analizado casos en donde se les había comunicado a los empleados que el período de su contrato laboral finaliza en determinada fecha y que no se renovará. Las sentencias 189-Apl-2011 (3 de octubre de 2012) y 115-Apl-2011 (25 de abril de 2012) resuelven esta situación, ${ }^{20}$ y ambas sentencias expresan que el 
contrato laboral no cumple con los requisitos exigidos para entenderse como trabajo temporal y, por tanto, son servicios de carácter permanente. Por ejemplo: la sentencia 115Apl-2011 trata el caso del contrato temporal de un agente de seguridad en el Centro Penal de Seguridad de Zacatecoluca.

Desde el punto de vista doctrinario, Carretero (2008: 3) argumenta que "la fijación del trabajador al puesto de trabajo se desmorona ante la generalización del trabajo temporal". Además, afirma que en Brasil el trabajo temporal se ha convertido en una vía de precarización (Carretero, 2008: 3).

Adamini (2011: 54) señala que el "Consenso de Washington" es un conjunto de recomendaciones que intentan flexibilizar la producción y la fuerza de trabajo (fueron aplicadas por Argentina), y afirma que se obtuvo un aumento en los factores señalados, pero que generó a su vez precariedad laboral, desempleo y no hubo crecimiento en el salario de los trabajadores.

Ahora que ya ha finalizado la explicación sobre el contrato por tiempo indefinido y temporal, se retoma nuevamente el contrato laboral de Transactel. El lugar donde se prestan los servicios es en las oficinas de la compañía. El horario tiene el primer indicador interesante para efectos de su estudio. El horario es de lunes a viernes, de 8:00 a.m. a 5:00 p.m., y los sábados de 8:00 a.m. a 12:00 m. Esto quiere decir que el trabajador realizará 9 horas diarias de lunes a viernes y los sábados de 4 horas, por lo que su jornada semanal es de 49 horas. Lo anterior viola el artículo 38 numeral 6 de la Constitución y el artículo 161 del Código de Trabajo, ya que son 8 horas máximo por día y 44 semanales. Esto provoca que dicha cláusula se considere como no escrita y se tendrá que acordar un horario que cumpla con los límites máximos legales.

El salario es de US\$250.00 y además tiene un bono con base en métricas, por lo que la forma de estipulación del salario es de sistema mixto, según lo mencionado en el contrato laboral y en el artículo 126 (literal c) del Código de Trabajo. Sin embargo, no se dan detalles de la forma de calcular el bono que menciona el contrato ni se encuentra regulado por el reglamento interno de trabajo.

Existe una cláusula razonable de exigir al trabajador que no labore en otra empresa que se dedique a la prestación de servicios de call center. Finalmente, hay una cláusula de confidencialidad que consiste, según el contrato, en la prohibición de revelar cualquier clase de información que no es del dominio general del negocio o industria; es decir, prohíbe revelar los secretos de la empresa. 
Respecto del reglamento interno de trabajo de Transactel, se puede decir que es una transcripción casi literal del Código de Trabajo, pero variando el orden de los artículos. Por otro lado, una cuestión interesante es que el reglamento expresa en su artículo 8 los distintos horarios y los separa por una hora, por ejemplo: de 8:00 a.m. a 12:00 m. y de 1:00 a 5:00 p.m.; pero en el contrato laboral revisado ${ }^{21}$ no hace esta distinción y no aparece regulado este horario en el reglamento interno de trabajo, por lo que el mismo contrato viola el reglamento.

\section{Digitex}

Este contrato está firmado por una trabajadora de 23 años de edad que tendrá el cargo de gestora y entre sus funciones están "realizar y contestar llamadas, asesoría a clientes, hacer reportes, brindar atención al cliente y otras funciones asignadas por su Jefe Inmediato Superior".

El contrato es de tiempo indefinido y el lugar de prestación de servicios será en las oficinas de la compañía. El horario de trabajo es de lunes a viernes de 9:00 a.m. a 1:00 p.m. y de 2:00 a 6:00 p.m. y sábados de 10:00 a.m. a 2:00 p.m. Este horario respeta la jornada laboral de las 8 horas diarias y 44 horas semanales.

El salario mensual es de US\$224.10, por lo que viola el salario mínimo, ${ }^{22}$ ya que el valor del día es de US\$7.47 y en los meses de 31 días no se le paga al trabajador un día entero. Esto contradice los artículos 1 (literal a) ${ }^{23}$ y $2^{24}$ del decreto $N^{\circ} 56$ del Órgano Ejecutivo, y además entra en la prohibición del artículo 5 (literal a) ${ }^{25}$ del mismo decreto, por lo que la sanción es tenerse por no escrito según el artículo $3^{26}$ del mismo decreto. Finalmente, al igual que en Transactel, existe la cláusula de exclusividad y de confidencialidad en similares términos que los detallados en el contrato anterior.

\section{Stream}

Es un contrato laboral firmado por un trabajador de 25 años que tendrá el cargo de "representante de soporte técnico I y ventas (inglés)". El contrato hace referencia al reglamento interno de trabajo, manuales de organización y operaciones, las instrucciones específicas dictadas por la empresa, las directrices y políticas establecidas. Hay una cuestión interesante y es que no se expresa en ningún momento en el contrato la entrega de toda esta documentación y tampoco explica en una forma clara y concreta las funciones que realizará.

El contrato será por tiempo indefinido y aclara que los primeros 30 días serán de prueba, lo cual está acorde al artículo 28 del Código de Trabajo. Además el lugar de prestación para los servicios será en las instalaciones de la compañía. Se añade que el horario de trabajo será 
de 8 horas en jornada diurna y de 7 horas en jornada nocturna, no excediendo las 44 horas ni las 39 horas semanales, respectivamente. Además, el horario inicial será de lunes a viernes de 7:00 a.m. a 12:00 m. y de 1:00 a 4:00 p.m., y los sábados de 8:00 a.m. a 12:00 m. Asimismo señala ciertas reglas generales de los horarios rotativos a los cuales se somete el trabajador.

El salario mensual es de US\$590.00, lo cual es más del doble si lo relacionamos con el salario de las otras compañías, y no está de más decir que excede el salario mínimo establecido por los decretos ejecutivos $N^{\circ} 56$ y 104.

Una cuestión interesante de este contrato es que establece contractualmente la evaluación de la eficiencia y efectividad. En caso de no satisfacer los parámetros mínimos, se considerará como negligencia del trabajador.

El contrato, al igual que las otras dos compañías, tiene una cláusula de exclusividad para que el trabajador no realice labores similares a ésta. Una última cuestión favorable y próspera para la empresa es que tiene una cláusula de propiedad intelectual que consiste básicamente en que será de la compañía los derechos patrimoniales de los inventos o descubrimientos que realice el trabajador usando recursos o información de la empresa. Además establece una presunción que el invento o creación es de la telefónica siempre y cuando sean conocimientos adquiridos en razón del rango o de las actividades encomendadas al empleado.

\section{Atento}

El reglamento interno de trabajo utiliza, en su mayoría, los artículos que regulan la situación laboral del Código de Trabajo, similar al caso de Transactel. De igual forma, el reglamento establece los distintos horarios en su artículo 24.

Un dato muy importante es que el reglamento interno de trabajo señala que la empresa no requerirá exámenes de VIH-SIDA, prueba de embarazo ni constancia de no afiliación sindical a las personas que quieran ingresar a su empresa, todo lo anterior según el artículo 11.

\section{SYKES}

Al igual que Transactel y Atento, el reglamento interno de trabajo de SYKES emplea en su mayoría los artículos del Código de Trabajo. De la misma forma que Atento, establece en su artículo 8 que no solicitará prueba de embarazo ni examen de VIH-SIDA ni la constancia de no afiliación sindical.

Otros puntos importantes consisten en que: a) el artículo $7 \mathrm{n}^{\circ} 2$ señala que el personal deberá ser mayor de edad y que solo admitirá menores de edad si tienen el permiso extendido por el Ministerio 
de Trabajo, b) el artículo 11 indica que los contratos individuales de trabajo serán de plazo indefinido, c) los artículos 52 al 54 tratan sobre mecanismos de denuncia de acoso sexual y d) el artículo 73 menciona una política de "puertas abiertas" que consiste básicamente en generar un mecanismo para escuchar las solicitudes de los trabajadores sin que estos últimos se preocupen de ser acosados o de cualquier otro tipo de represalia.

\section{DELL}

Similar a las demás empresas, usa en su mayoría el Código de
Trabajo en el reglamento interno de trabajo. Como características particulares, no admiten menores de edad según el artículo $11 \mathrm{n}^{\circ} 2$ y tiene regulada de una forma muy detallada las disposiciones disciplinarias (artículos 93 y 94).

Los contratos, según el artículo 15 , pueden ser temporal o de tiempo indefinido y en los documentos para seleccionar personal, no solicitarán prueba de embarazo, VIH-SIDA ni constancia de no afiliación sindical (artículo 12). Similar a SYKES, tiene una política de puertas abiertas (artículo 92).

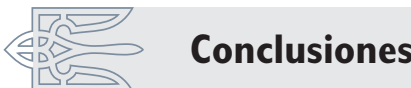

Se ha estudiado a lo largo de esta investigación la situación laboral de los jóvenes en El Salvador desde una perspectiva jurídica y económica, siendo este espacio donde éstas convergerán para presentar los resultados:

La legislación estudiada garantiza unos mínimos a favor de los menores y de cualquier persona en general en lo relativo a la relación laboral, incluyendo el salario, la salud, ISSS, AFP y prestaciones laborales, entre otros. Sin embargo, esto no implica que en la práctica se generen las condiciones laborales necesarias para que los jóvenes puedan adaptarse favorablemente en el mercado de trabajo.

Respecto del salario, se ha incrementado en 2013 en un 12\% respecto del año 2011, pero el aumento será de forma progresiva hasta alcanzar dicho porcentaje el 1 de enero de 2015. Esto podría tener un impacto positivo sobre la cobertura de la Canasta Básica Alimentaria y Ampliada; sin embargo, dicho efecto dependerá de los cambios en los precios de los productos que abarca la referida canasta.

La mayoría de jóvenes ocupados se ubican en categorías ocupacionales y ramas económicas que generan menores ingresos al ser comparados con los adultos (personas de 30 años o más), lo que limita la cobertura de la CBAAR y la CBAAU.

La tasa de desempleo juvenil es más alta que la de los adultos, desde el año 2007 a 2012, lo cual 
podría indicar que los jóvenes son uno de los grupos etarios más afectados por la situación económica que está pasando El Salvador.

Los contratos laborales y reglamentos internos de trabajo de los call centers, en su mayoría, respetan los mínimos legales exigidos, pero es necesario profundizar en otro estudio lo relativo a la práctica al interior de estas empresas, puesto que esta investigación solamente se encarga de analizar la legalidad de la referida documentación.

\section{Bibliografía}

os (1950) Código Sustantivo del Trabajo. Decreto Ley No. 2663, Diario Oficial No. 27.407. Colombia.

os (1976) Ley No. 20.744 Ley de Contrato de Trabajo. Decreto 390/1976, Boletín Oficial. Argentina.

os Adamini, M., (2011) "La precarización laboral oculta en las pasantías universitarias. Cambios y continuidades en su nueva ley", en Revista Derecho y Ciencias Sociales. No. 4. Abril 2011. Argentina, pp. 51-63.

os Asamblea Constituyente, (1983) Constitución de la República. Decreto Constitucional No. 38, Diario Oficial No. 234, tomo No. 281. El Salvador.

o3 Asamblea Legislativa, (1953) Ley del Seguro Social. Decreto Legislativo No. 1263, Diario Oficial No. 226, tomo 161. El Salvador.

os Asamblea Legislativa, (1972) Código de Trabajo. Decreto Legislativo No. 15, Diario Oficial No. 142, tomo 236. El Salvador.

cos Asamblea Legislativa, (1996) Ley del Sistema de Ahorro para Pensiones. Decreto Legislativo No. 927, Diario Oficial No 243, tomo 333. El Salvador.

os Asamblea Legislativa, (2000) Ley de Integración Monetaria. Decreto Legislativo No. 201, Diario Oficial No 241, tomo 349. El Salvador.

os Asamblea Legislativa, (2009) Ley de Protección Integral de la Niñez y Adolescencia. Decreto Legislativo No. 839, Diario Oficial No. 68, tomo 383. El Salvador.

os Asamblea Legislativa, (2012) Ley General de Juventud. Decreto Legislativo No. 910, Diario Oficial No. 24, tomo 394. El Salvador.

os Banco Central de Reserva (BCR), Revista Trimestral. Tercer trimestre de 2012. 
os Cabanellas, G., (2001) Compendio de Derecho Laboral, tomo I. Argentina.

os Carretero, J., (2008) "La imparable crisis del derecho del trabajo", en revista Nómadas. Revista Crítica de Ciencias Sociales y Jurídicas. No. 19(3). 2008. España, pp. 415-420.

os Dirección General de Estadísticas y Censos (DIGESTYC), Encuesta de Hogares de Propósitos Múltiples. Años 2007 a 2011. Ministerio de Economía. El Salvador.

os Iciar, M., (2003) "Nociones de juventud", en revista Última década. No. 18. Abril 2003. México, pp. 11-19.

os Imprenta Nacional, Decretos Ejecutivos: Tarifas de Salarios Mínimos. [En línea]. El Salvador, disponible en: http://imprentanacional.gob.sv/index. php/novedades/avisos/25-the-cms/228-avisos-ciudadano

os Magulis, M. (revisado en 2013) "Juventud: una aproximación conceptual".

os Marcucci, C., (2005) "Panorama contextualizado del derecho sustancial laboral colombiano". Colombia.

os Max-Neef, M., (1993) Desarrollo a escala humana: conceptos, aplicaciones y algunas reflexiones. Editorial Nordan-Comunidad. [En línea]. Montevideo, Uruguay, disponible en: http://www.max-neef.cl/descargas/ Max_Neef-Desarrollo_a_escala_humana.pdf

os Naciones Unidas, (2008) Situación y desafíos de la juventud en Iberoamérica. El Salvador.

os Organización Internacional del Trabajo (OIT), (1946) Convenio sobre el examen médico de los menores (industria). Montreal. Convenio No. 77.

os Organización Internacional del Trabajo (OIT), (1973) Convenio sobre la edad mínima. Ginebra. Convenio No. 138.

os Organización Internacional del Trabajo (OIT), (1973) Convenio sobre la edad mínima. Ginebra.

os Organización Internacional del Trabajo (OIT), (1999) Convenio sobre las peores formas de trabajo infantil. Convenio No. 182.

os Organización Internacional del Trabajo (OIT), (2013) "Trabajo decente". [En línea].

os Órgano Ejecutivo, (1860) Código Civil. Gaceta Oficial No. 85, tomo No. 8. El Salvador. 
os Órgano Ejecutivo, (1954) Reglamento para la Aplicación del Régimen del Seguro Social. Decreto Ejecutivo No. 37, Diario Oficial No. 88, tomo 163. El Salvador.

os Órgano Ejecutivo, (2011) Tarifa de Salario Mínimo para los Trabajadores Agropecuarios. Decreto Ejecutivo No. 54, Diario Oficial No. 85, tomo 391. El Salvador.

os Órgano Ejecutivo, (2011) Tarifa de Salario Mínimo para los Trabajadores de Recolección de Cosechas de Café, Algodón y Caña de Azúcar. Decreto Ejecutivo No. 55, Diario Oficial No 85, tomo 391. El Salvador.

os Órgano Ejecutivo, (2011) Tarifa de Salario Mínimo para los Trabajadores del Comercio, Servicios, Industria, Maquila Textil y Confección. Decreto Ejecutivo No. 56, Diario Oficial No. 85, tomo 391. El Salvador.

os Órgano Ejecutivo, (2011) Tarifa de Salario Mínimo para los Trabajadores de las Industrias Agrícolas de Temporada. Decreto Ejecutivo No. 57, Diario Oficial No. 85, tomo 391. El Salvador.

os Órgano Ejecutivo, (2013) Tarifa de Salario Mínimo para los Trabajadores Agropecuarios. Decreto Ejecutivo No. 103, Diario Oficial No. 119, tomo 400. El Salvador. Ministerio de Trabajo y Previsión Social. [En línea]. El Salvador, disponible en: http://mtps.gob.sv/index.php?option=com_phoca download\&view=category\&id=27:decretos\&download=170:decretos-deaumento-al-salario-mnimo-decreto-aumento-salario-minimo\&ltemid=139

os Órgano Ejecutivo, (2013) Tarifa de Salario Mínimo para los Trabajadores del Comercio y Servicios, Industria y Maquila Textil y Confección. Decreto Ejecutivo No. 104, Diario Oficial No. 119, tomo 400. El Salvador. Ministerio de Trabajo y Previsión Social. [En línea]. El Salvador, disponible en: http://mtps.gob.sv/index.php?option=com_phocadow nload\&view=category\&id=27:decretos \&download=170:decretos-deaumento-al-salario-mnimo-decreto-aumento-salario-minimo\&ltemid=139

os Órgano Ejecutivo, (2013) Tarifa de Salario Mínimo para los Trabajadores de Recolección de Cosechas de Café, Algodón y Caña de Azúcar. Decreto Ejecutivo No. 105, Diario Oficial No. 119, tomo 400. El Salvador. Ministerio de Trabajo y Previsión Social. [En línea]. El Salvador, disponible en: http://mtps.gob.sv/index.php?option=com_phocadow nload \&view=category\&id=27:decretos \&download=170:decretos-deaumento-al-salario-mnimo-decreto-aumento-salario-minimo\&ltemid=139

os Órgano Ejecutivo, (2013) Tarifa de Salario Mínimo para los Trabajadores de las Industrias Agrícolas de Temporada. Decreto Ejecutivo No. 106, Diario Oficial No. 119, tomo 400. El Salvador. Ministerio de Trabajo y Previsión Social. [En línea]. El Salvador, disponible en: http://mtps.gob. 
sv/index.php?option=com_phocadownload\&view=category\&id=27:dec retos\&download=170:decretos-de-aumento-al-salario-mnimo-decretoaumento-salario-minimo\&ltemid $=139$

os Sabogal, E., (2012) "Guía Laboral 2012". Colombia.

os Sala de lo Civil de la Corte Suprema de Justicia, Expediente 115-Ap/2011, Sentencia, 25 de abril de 2012.

os Sala de lo Civil de la Corte Suprema de Justicia, Expediente 189-Ap/2011, Sentencia, 3 de octubre de 2012.

os Torres, C. y Millán, N., (2001) "La juventud española", en revista Aedipe. Asociación Española de Dirección de Personal. No. Extra 19, pp. 14-28.

os Urcola, M., (2003) "Algunas apreciaciones sobre el concepto sociológico de juventud", en revista Invenio. Volumen 6, número 011. Universidad del Centro Educativo Latinoamericano. Argentina, pp. 41-50.

Notas

1 Es importante tener en cuenta que los tratados internacionales y las leyes secundarias son de igual rango, pero en caso de conflicto entre ambas, prevalece el tratado. Cuando se refiere a leyes secundarias, éstas tienen igual rango, pero existe preferencia entre las mismas cuando hablan de temas especiales.

2 Desde 2007, la DIGESTYC establece los 16 años como la cota inferior de edad para estar incluido en la Población en Edad de Trabajar (PET).

3 El artículo 105 de la Ley de Contrato de Trabajo (LCT) autoriza el pago de la remuneración en especie y el artículo 107 del mismo cuerpo legal establece un pago máximo en especie del $20 \%$ de la remuneración.

$4 \quad$ El artículo 127 del Código Sustantivo del Trabajo (CST) señala como elementos integrantes del salario el pago en especie y el artículo 129 establece que no podrá exceder del 50\% de la remuneración; sin embargo, si el trabajador

gana el mínimo, no podrá exceder del $30 \%$.

5 Según el Ministerio de Trabajo y Previsión Social y la Imprenta Nacional (encargada de publicar el Diario Oficial), los decretos aparecerán en el Diario Oficial del 1 de julio de 2013. Para evitar una confusión en el lector, es necesario mencionar que el Diario Oficial aparece de forma retrasada, por lo que la fecha que indica el documento no coincide con la que en verdad salió publicada. A modo de ejemplo, en el día 11 de julio aparece publicado el Diario Oficial del 13 de junio, por lo que dicho retraso es de casi un mes.

6 Existe armonía con el artículo 60 LEPINA y el artículo 116 del Código de Trabajo, porque expresan las mismas cantidades de horas por día y por semana y también prohíben el trabajo nocturno.

7 Actualmente Procuraduría General de la República. 
8 La LEPINA fue presentada en el decreto legislativo $\mathrm{N}^{\circ} 839$ del 26 de marzo de 2009 y publicada en el Diario Oficial No. 68, tomo $\mathrm{N}^{\circ} 383,19$ de abril de 2009. Cuando hablamos de leyes secundarias, éstas tienen igual rango, pero existe preferencia entre las mismas cuando hablan de temas especiales; y en este caso, la LEPINA, al ser una ley especial en comparación al Código de Trabajo, por ser su objeto la protección de los niños y adolescentes, prevalece sobre éste $y$, por tanto, se tiene que modificar el Código de Trabajo.

9 Lo cual era inconstitucional visto que contradecía el artículo 38 ( $\left.\mathrm{n}^{\circ} 10\right)$ de la Constitución. Es de aclarar que existe una jerarquía entre las leyes secundarias (como el Código de Trabajo, CC, LEPINA) y la Constitución. Esta última es la norma fundamental y cualquier ley que la contradiga es inconstitucional, pero existe un proceso específico para que se dé esta declaración.

10 Artículo 21, párrafo 4.

11 Se aclara que en el caso de que exista contradicción entre la Constitución y los tratados internacionales, prevalecerá la Constitución.

12 Artículo 105 del Código de Trabajo: "Se prohíbe el trabajo de los menores de dieciocho años en labores peligrosas o insalubres. Sin embargo, se podrá autorizar el trabajo de menores a partir de la edad de dieciséis años, siempre que quedan plenamente garantizadas su salud, seguridad y moralidad y que éstos hayan recibido instrucción o formación profesional adecuada y específica en la rama de la actividad correspondiente".

13 Artículo 46 del Reglamento para la Aplicación del Régimen del Seguro Social.
14 Artículo 16 de la Ley del Sistema de Ahorro para Pensiones.

15 Cálculos de tasas de crecimiento promedio se realizaron con base en datos del Banco Central de Reserva (BCR).

16 Para la obtención de los salarios, se filtraron las bases de datos por la Población Económicamente Activa (PEA), que fue calculada con las preguntas 403, 404 y 406 de la boleta de la encuesta.

17 Se ha calculado con base en la PEA total para dos cuestiones: a) medir su aporte al desempleo nacional y b) para que sea comparable con la tasa de desempleo nacional. Es importante señalar que esta forma de cálculo permite una comparación real entre las distintas tasas de desempleo, lo cual no es posible hacer con la forma usual de calcular la tasa de desempleo juvenil a partir de la PEA juvenil.

18 No está de más aclarar que la Oficina de Información y Respuesta cumplió con el plazo señalado en el artículo 36 (literal c, inciso 2) de la Ley de Acceso a la Información Pública.

19 Las fotocopias de los contratos laborales tienen suprimidas los datos generales que puedan identificar tanto al empleado como al empleador.

20 Las demandas eran contra el Estado, pero se aplica el Código de Trabajo.

21 De lunes a viernes de 8:00 a.m. a 5:00 p.m., y los sábados de 8:00 a.m. a 12:00 m.

22 Recordar que se analiza el salario mínimo aprobado en el año 2011 y no el de 2013 porque estos contratos laborales se firmaron antes de la última actualización del salario mínimo.

23 Artículo 1 literal a. Los trabajadores del Comercio y Servicio que laboren 
en cualquier lugar de la República, devengarán por jornada ordinaria de trabajo diario diurno SIETE DOLARES CUARENTA Y SIETE CENTAVOS (\$7.47), equivalente a CERO PUNTO NUEVE TRES CUATRO DE DÓLAR (\$0.934) por hora.

24 Artículo 2. El pago de las prestaciones que establece el Código de Trabajo a favor de los trabajadores a quienes se refiere este Decreto, como días de asueto, vacaciones, aguinaldo, indemnizaciones y otras, se hará con base al salario mínimo, excepto cuando el salario estipulado sea mayor.
25 Artículo 5. Se prohíbe a los patronos alterar en perjuicio de sus trabajadores las condiciones de trabajo que prevalezcan en la empresa al entrar en vigencia este Decreto, especialmente: a) Reducir los salarios que pagan en virtud de contratos de trabajo, reglamentos internos o costumbres de empresa.

26 Los derechos establecidos en este Decreto a favor de los trabajadores son irrenunciables y los acuerdos, pactos o contratos que los contravengan no tendrán valor alguno. 